\title{
Anatomia Quantitativa e Degradação in vitro de Tecidos em Cultivares de Capim- Elefante (Pennisetum purpureum Schumach.)
}

\author{
Cláudio José Freixieiro Alves de Brito ${ }^{1}$, Roberto Antonio Rodella ${ }^{2}$, Francisco Carlos \\ Deschamps $^{3}$, Yedo Alquini ${ }^{4}$
}

\begin{abstract}
RESUMO - Neste trabalho quantificaram-se as principais alterações histológicas ocorridas em cultivares de capim-elefante (Pennisetum purpureum Schumach.), em três estádios de desenvolvimento. A degradação dos tecidos foi avaliada após incubação em líquido ruminal de bovinos. As porcentagens de tecidos presentes em colmo, quilha, limbo e bainha foliares foram determinadas. A quilha e o colmo apresentaram maior proporção de tecido lignificado, enquanto o limbo foliar, maior quantidade de tecido epidérmico e tecido vascular não-lignificado. O tecido parenquimático foi encontrado em menor proporção na bainha foliar, principalmente pela presença do aerênquima, a partir da segunda coleta. A proporção de tecido lignificado aumentou com a maturidade do vegetal, sendo mais acentuado em colmos e limbos. Entre as principais alterações, destaca-se a grande área de degradação encontrada na bainha foliar, mesmo com o envelhecimento dos tecidos. Isto foi associado à presença do aerênquima encontrado nos estádios de desenvolvimento mais avançados. Os estômatos favoreceram a penetração dos microorganismos nos tecidos mais internos da folha (mesofilo). O espessamento e a lignificação da parede celular ocorreram com o envelhecimento das plantas, acompanhado de redução na área de degradação dos tecidos.
\end{abstract}

Palavras-chave: anatomia vegetal, degradação de tecidos, forrageira, lignina, parede celular, ruminante

\section{Quantitative Anatomy and in vitro Tissue Degradation in Elephant Grass (Pennisetum purpureum Schumach.) Cultivars}

\begin{abstract}
In this research, the main histological changes that occurred in cultivars of elephant-grass (Pennisetum purpureum Schumach.) at three development stages were determined. The tissue degradation was evaluated after incubation in cattle ruminal fluid. The percentage of tissues presented in the stem, keel, leaf limbo and sheath were determined. The keel and the stem presented greater proportion of lignified tissues, while the leaf limbo presented higher amount of epidermal and non-lignified vascular tissues. The parenchymal tissue was found in minor proportion on the leaf sheath, mainly by the presence of aerenchyma, from the second collection. The proportion of lignified tissues increased with the grass maturity, being more accentuated in stems and limbo. Among the main changes, stand out the greater degradation area found for leaf sheath, even with the tissue become older. This was associated with the presence of aerenchyma found in the advanced development stages. The stomata propitiated intrude of the microorganisms in the most internal leaf tissues (mesofilo). The thickness and lignification of the cell walls occurred as the grass become older, getting along with the reduction in the tissue degradation area.
\end{abstract}

Key Words: plant anatomy, tissue degradation, forage, lignin, cell wall, ruminant

\section{Introdução}

O capim-elefante (Pennisetum purpureum Schumach.) é uma das forrageiras mais utilizadas para alimentação de bovinos em regiões tropicais, tendo sido bastante estudado quanto às suas características agronômicas e nutricionais (OTERO, 1961; ANDRADE e GOMIDE, 1971; e CORSI, 1972). Entretanto, poucos trabalhos foram realizados relacionando as características anatômicas com os processos de digestão ruminal.

Estudos da anatomia foliar e suas relações com o valor nutricional de plantas forrageiras foram relatados por WILKINS (1972), WILSON (1976), RODELLA et al. (1982, 1984), VENTRELLA et al. (1997a, 1997b) e ALVES DE BRITO et al. (1997). Nesses trabalhos, verificou-se a possibilidade de se associar a proporção de tecidos esclerenquimáticos e vasculares à qualidade nutricional de uma espécie forrageira. AKIN et al. (1973) constataram que a presença ou a quantidade de determinados tecidos influi na digestibilidade de uma forrageira, sugerindo diferenciadas taxas de degradação em relação aos

\footnotetext{
${ }^{1}$ M.Sc. em Botânica, Doutorando do Curso de Pós-Graduação em Botânica, UNESP - Botucatu, Cx. Postal 510, 18618-000, Botucatu, SP, Brasil. Bolsista da CAPES. e.mail: cjbrito@zipmail.com.br

2 Prof. Assistente-Doutor, Depto. de Botânica, IBB-UNESP, Cx. Postal 510, 18618-000, Botucatu, SP. e.mail: rodella@ibb.unesp.br

${ }^{3}$ Pesquisador-Doutor, EPAGRI-S/A, C. Postal 277, 88301-970, Itajaí, SC. Bolsista do CNPq.

${ }^{4}$ Prof. Adjunto, Depto. de Botânica, UFPR, Cx. Postal 19031, 81531-970, Curitiba, PR.
} 
diferentes tecidos vegetais. De modo geral, verificase que maiores quantidades de tecidos lignificados e esclerenquimáticos proporcionam menores taxas de digestibilidade (WILSON, 1976; ALVES DE BRITO, 1997; ALVES DE BRITO et al., 1997; e VENTRELLA et al., 1997a e 1997b.).

A importância da determinação das porcentagens dos distintos tecidos presentes nos diferentes órgãos vegetativos está associada com a área e o peso seco destes tecidos em cada órgão (AKIN et al., 1983; AKIN, 1989; e WILSON, 1993).

Com o envelhecimento do vegetal, ocorre espessamento e lignificação das paredes celulares, principalmente nas regiões dos feixes vasculares, reduzindo assim as áreas de digestão dos tecidos (AKIN et al., 1973; HANNA et al., 1973). WILKINS (1969) observou que alguns tecidos permanecem intactos, mesmo após prolongado tempo de digestão in vitro, indicando que as características anatômicas da planta limitam a degradação dos tecidos vegetais.

O uso de técnicas microscópicas na avaliação da digestão de forrageiras é importante ferramenta que auxilia na elucidação de fatores que influenciam a sua degradação pelos microorganismos do rúmen. Em estudos de microscopia são encontradas diferenças na anatomia da planta e dos gradientes de lignificação que afetam a digestibilidade entre espécies e partes da planta (AKIN, 1989).

No presente trabalho, acompanhou-se o crescimento de três cultivares de capim-elefante, determinando-se a porcentagem dos diferentes tecidos presentes na folha e no colmo, avaliando a seqüência de degradação dos tecidos após a incubação in vitro em líquido ruminal de bovinos.

\section{Material e Métodos}

Os cultivares (Roxo, EMPASC 307 Testo e EMPASC 309 Areia) de P. purpureum Schumach. foram implantados na Estação Experimental da EPAGRI, Município de Itajaí - SC, encontrando-se sob mesmas condições edafoclimáticas.

As amostras coletadas com cinco repetições por cultivar constituíram-se de frações de colmo, bainha e lâmina foliar após 4,8 e 16 semanas do corte de uniformização realizado a $30 \mathrm{~cm}$ do solo, efetuado em 16/11/1994. Uma vez coletadas, as amostras foram fixadas em F.A.A. 50\% (JOHANSEN, 1940).

$\mathrm{Na}$ primeira coleta, foram retiradas frações da porção mediana da lâmina e bainha foliar, da terceira folha com lígula exposta, contando-se a partir do ápice da planta. A amostra de colmo foi retirada da porção mediana do entrenó recoberto pela referida bainha. Na segunda coleta, as frações foram retiradas da quinta folha e, na terceira coleta, da décima primeira folha, seguindo-se os mesmos procedimentos realizados na primeira coleta.

Para o estudo anatômico quantitativo, as amostras foram emblocadas em glicol metacrilato (GMA) JB-4 (Polysciences, Inc.). Posteriormente, foram seccionadas transversalmente em micrótomo rotatório, distendidas em água e coradas, utilizando-se solução aquosa de Fucsina Básica 0,0125\% e Azul de Astra 1\% (ALVES DE BRITO e ALQUINI, 1996). A lâmina foliar foi dividida em duas regiões: quilha (nervura central) e limbo (asa), de acordo com a terminologia proposta por METCALFE (1960). Juntamente com o colmo e a bainha foliar, as secções foram desenhadas com auxílio de microscópio de projeção e os tecidos mensurados em mesa digitalizadora, acoplada a microcomputador, como descrito por ALVES DE BRITO (1997).

Os tipos de tecidos foram separados de acordo com a natureza das paredes celulares, considerando a seguinte divisão: tecido epidérmico (excluindo-se tricomas e células buliformes), tecido parenquimático (incluindo células buliformes e bainha parenquimática do feixe vascular), tecido vascular lignificado + esclerênquima (incluindo xilema, fibras, bainhas esclerenquimáticas e outras células presentes nos feixes vasculares que apresentassem parede celular de natureza lignificada) e tecido vascular nãolignificado (incluindo floema e outras células presentes nos feixes vasculares que apresentassem parede celular de natureza celulósica).

As células buliformes (Figura 2-A), apesar de pertencerem ao tecido epidérmico, apresentam grande parte de seu volume situada no mesófilo. Suas paredes, bem mais delgadas que as epidérmicas (CARO e SANCHES, 1969; ESAU, 1982), assemelham-se muito às células do mesofilo e, por isto, foram incluídas na porcentagem de tecido parenquimático do limbo foliar.

$\mathrm{O}$ aerênquima, quando presente, foi mensurado e subtraídodaárea de tecido parenquimático da bainhafoliar.

Os dados obtidos da análise anatômica quantitativa foram transformados em $\operatorname{arc} \operatorname{sen} \sqrt{x}$ e, posteriormente, submetidos à análise de variância, sendo as médias comparadas por intermédio do teste Duncan a $5 \%$ de probabilidade.

Para se proceder aos estudos da degradação in vitro, foram utilizados tubos de ensaio contendo $6 \mathrm{ml}$ 
da solução de McDougall (McDOUGALL, 1948) mantidos a $39^{\circ} \mathrm{C}$, onde foram colocadas as frações em estudo (porções de 0,1-0,2 cm de colmo, bainha e lâmina foliar). O líquido ruminal foi coletado de bovinos adultos da raça holandesa, filtrado em tecido fino e levado ao laboratório a $39^{\circ} \mathrm{C}$, sob ambiente de $\mathrm{CO}_{2}$. A seguir, foram adicionados $4 \mathrm{ml}$ de líquido ruminal diluído em solução de McDougall na proporção 1:1 e mantidos sobre mesa agitadora em estufa a $39^{\circ} \mathrm{C}$. As amostras do material foram coletadas após 6, 24 e 48 horas de incubação, fixadas em glutaraldeído $3 \%$ com tampão fosfato por quatro dias e desidratadas em etanol, na sequiência de concentração de $10,30,50$ e $70 \%$, onde foram mantidas até o processamento final do material.

Para determinação da degradação dos tecidos, estas amostras foram emblocadas em glicol metacrilato e coradas como descrito para a mensuração dos tecidos. Paralelamente, prepararam-se amostras do material digerido para observação em microscopia eletrônica de varredura (MEV), por meio da desidratação via ponto crítico com $\mathrm{CO}_{2}$, metalização com ouro, sendo, posteriormente, observadas em microscópio Philips SEM 505, junto ao Centro de Microscopia Eletrônica da UFPR-Curitiba-PR.

\section{Resultados e Discussão}

A extensão da digestão dos tecidos vegetais depende da maior ou menor facilidade com que os microorganismos têm acesso aos tecidos mais profundos. Dessa maneira, a ação dos microorganismos ao longo dos tecidos depende do arranjo, do espessamento e da composição da parede celular.

As espécies forrageiras tropicais, entre elas o capim-elefante, apresentam grande potencial de produção. Entretanto, a acumulação de matéria seca ao longo do crescimento da planta é acompanhada do espessamento e do aumento de lignificação da parede celular, comprometendo, assim, sua qualidade como alimento para os ruminantes.

No presente trabalho, encontrou-se maior percentual de área de tecido lignificado e menor de tecido parenquimático no limbo e na quilha do cultivar 307 Testo (Tabela 1), sugerindo menor potencial de degradação ruminal nas lâminas foliares deste cultivar. A quilha e o colmo foram as estruturas onde as áreas de tecidos lignificados estavam mais presentes. No colmo, a área de lignificação pode ser associada à presença da bainha esclerenquimática que circunda os feixes vasculares (Figura 1-E). A lignificação e o espessamento da parede celular ocorre concomitantemente à maturação fisiológica dos vegetais e de forma mais acentuada nas gramíneas. Estas características apresentam implicações na utilização do material vegetal, quando destinado à alimentação de ruminantes (WILSON, 1993).

A bainha foliar apresentou menor quantidade de tecido parenquimático em relação às demais estruturas (Tabela 1), em parte devido à formação do aerênquima no mesofilo, observado a partir da segunda coleta (8 semanas). A presença do aerênquima, definido como estrutura cuja finalidade é proporcionar ambiente favorável à troca de gases, pode contribuir para facilitar a degradação da bainha. Neste caso, a desagregação do tecido facilita a disseminação dos microorganismos ruminais (AKIN, 1993), já que o aerênquima forma lacunas, originadas pelo rompimento de células do parênquima (Figura 1-B).

A área ocupada pelo tecido epidérmico apresentou pequena variação entre os cultivares estudados (Tabela 1). Sua presença é mais fortemente observada no limbo foliar, em parte devido ao maior tamanho de células deste órgão, em relação às demais estruturas (Figura 2-A). Com relação ao tecido vascular não-lignificado, verificou-se que apenas no colmo com média de $1,5 \%$, ocorreram diferenças entre os cultivares (dados não mostrados) e que o limbo foliar apresentou maior proporção deste tecido (média de $2,5 \%$ ). Representando o floema, este tecido dispensa maiores considerações no contexto do presente estudo, já que a área ocupada pelo tecido (pouco mais de $1 \%$ ) é pouco expressiva quando comparada à dos demais tecidos (Figuras 1-B e 2-C).

A determinação da área ocupada pelos principais tecidos dessas gramíneas forrageiras permite observar algumas tendências bastante definidas; entre elas o fato de que a área ocupada pelo tecido epidérmico tende a diminuir com o crescimento das plantas, especialmente na quilha e no limbo, onde é maior a participação deste tecido (Tabela 1). Tendência inversa é observada para o tecido lignificado, cuja área ocupada aumenta com a idade da planta, tanto na lâmina foliar (limbo + quilha) quanto no colmo. Por outro lado, parece não haver tendência tão definida para a área ocupada pelo tecido parenquimático, já que os valores pouco se alteraram nos diferentes órgãos dos cultivares ao longo do crescimento. As alterações marcantes observadas na bainha estão mais associadas à presença do aerênquima (Tabela 1). Dessa maneira, à medida que a planta se desenvolve, o aumento da área de lignificação pode justificar a redução na área de tecido epidérmico, pelo menos em termos percentuais. 
ALVES DE BRITO et al.

Tabela 1- Porcentagem dos diferentes tecidos presentes na folha e no colmo de cultivares de Pennisetum purpureum, ao longo de três períodos de crescimento (4, 8 e 16 semanas de rebrote)

Table 1 - Different tissue percentage present in Pennisetum purpureum leaves and stems, in three growing periods (4, 8 and 16 weeks after sprouting)

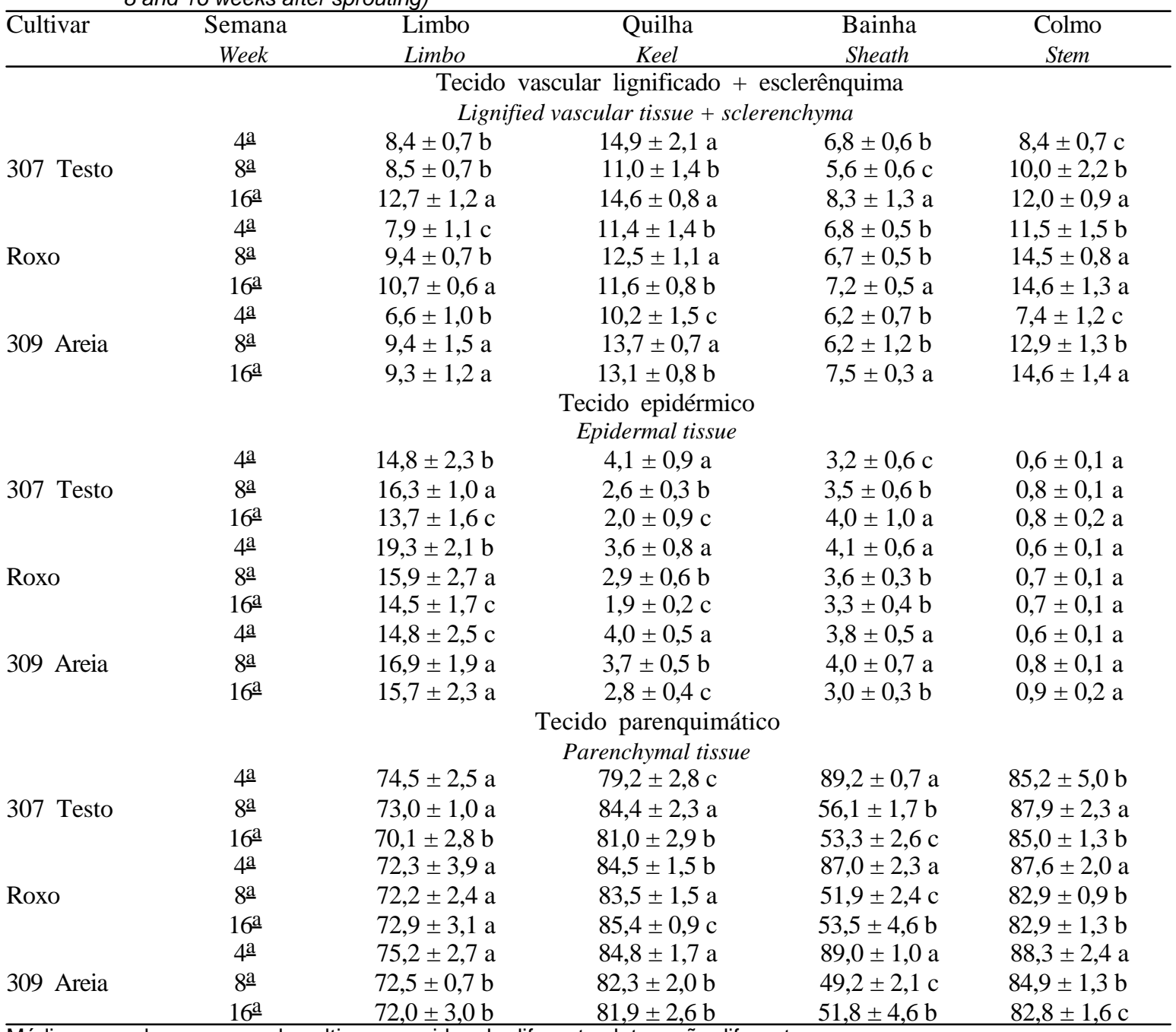

Médias, na coluna e em cada cultivar, seguidas de diferentes letras são diferentes.

Means, within a column and in each cultivar, followed by different letters are different.

Mesmo sem ter sido possível quantificar, em parte, a área de tecido degradado, porque algumas estruturas simplesmente desapareceram ao longo do processo de degradação ruminal, foi possível observar visualmente que a esta área diminuiu com o envelhecimento da planta. A bainha foliar foi exceção, por ter apresentado acentuado aumento na área de degradação, o qual foi atribuído à presença do aerênquima (Figura 1-B e C). As lacunas, representadas pelo aerênquima, favoreceram a movimentação dos microorganismos no interior do mesofilo, uma vez que o rompimento das células que circundam tais lacunas serviram como ponto inicial ao ataque da biota ruminal às paredes celulares. Isto não foi observado na primeira coleta, já que o aerênquima ainda não estava presente, havendo retardamento do ata- que às paredes celulares do mesofilo (Figura 1-A). Houve maior área de tecido degradado com o aumento do tempo de incubação, permanecendo apenas os tecidos mais resistentes, como também foi observado por WILKINS (1969).

As áreas mais resistentes compreenderam, basicamente, o xilema e o esclerênquima (Figuras 1-B e 2-C), a bainha esclerenquimática (Figura 1-C e E), a bainha parenquimática (Figura 2-B e D) e a epiderme (Figuras 1-C, 2-B e C). Com a utilização da MEV, foi possível observar que a biota ruminal digeriu quase que totalmente o tecido parenquimático (Figura 2-E), permanecendo os feixes vasculares limitados pela bainha esclerenquimática (Figura 2-G).

$\mathrm{Na}$ bainha foliar, observou-se que, nos períodos mais longos de incubação, os feixes vasculares fica- 

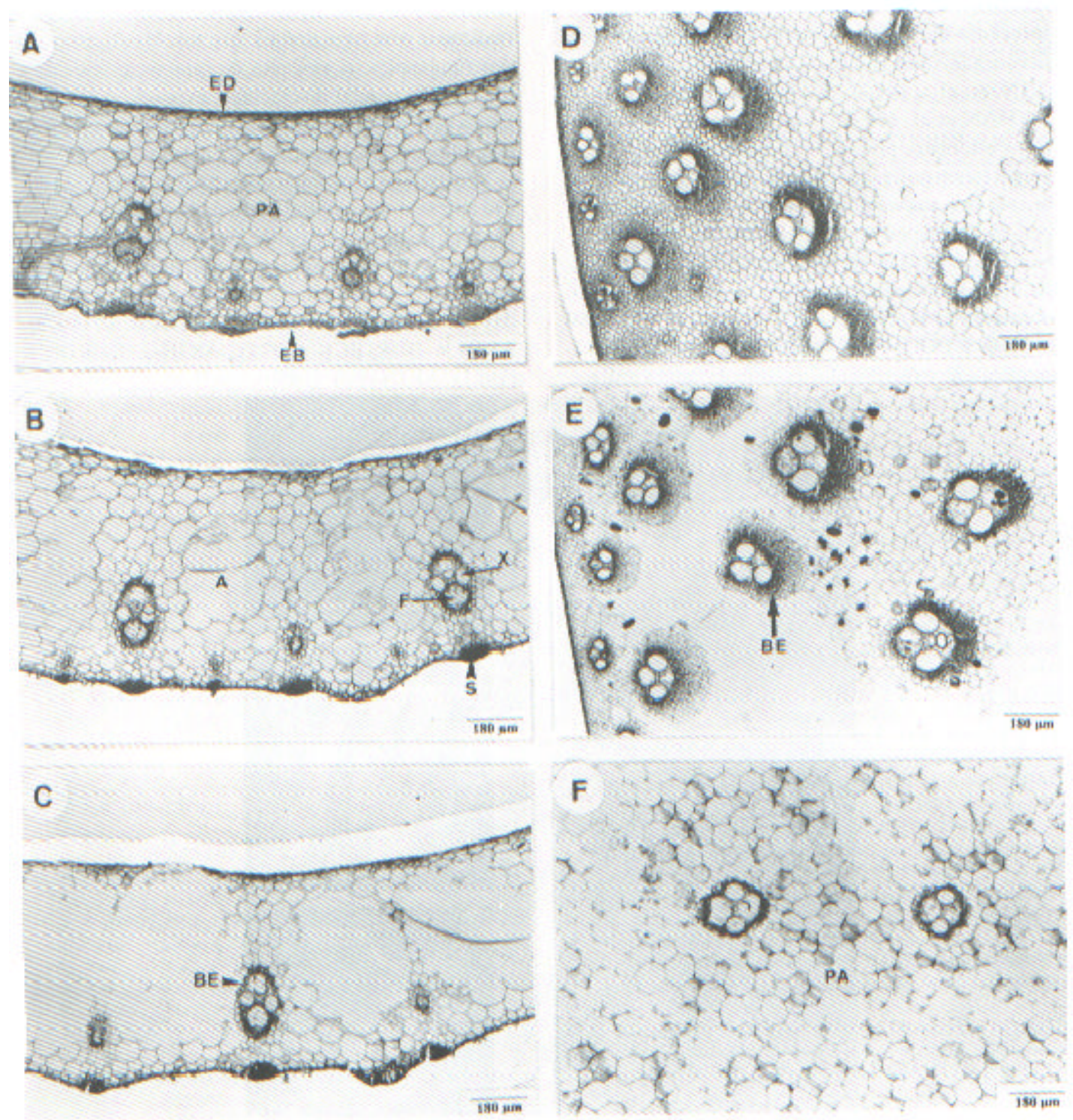

Figura 1 - Secções transversais de P. purpureum. Cv. 307-Testo. A - Bainha foliar não incubada; B - Após 24 h de incubação; C - Após 48 h; D- Colmo após 6 h; E - Após 24 h; F- Após 48 h. Epiderme adaxial (ED); epiderme abaxial (EB); parênquima ( $P A)$; aerênquima $(A)$; esclerênquima $(S)$; xilema $(X)$; floema $(F)$; bainha esclerenquimática $(B E)$.

Figure 1 - Cross-sections of P. purpureum. CV. 307-Testo. A-Leaf sheath non-incubated; B-Incubated for 24 h; C - For 48 ; $D$ - Stem for $6 h$; - For 24 h; F - For 48 h. Adaxial epidermis (ED); abaxial epidermis (EB); parenchyma (PA); aerenchyma (A); sclerenchyma $(S) ; x y l e m(X) ;$ phloem (F); sclerenchyma bundle sheath (BE). 
ram sustentados apenas pela epiderme da face abaxial, pois a epiderme da face adaxial foi parcial (Figura 1-C) ou totalmente digerida (Figura 2-F e G). Isto comprova que a epiderme, juntamente com a cutícula (Figura 2-B e C), representa barreira à aderência e penetração dos microorganismos ruminais, conforme sugerido por AKIN et al. (1973), HANNA et al. (1973) e LATHAN et al. (1978). Foi observado, também, que os estômatos presentes na epiderme de bainhas e lâminas foram utilizados pelosmicroorganismos como via de acesso aos tecidos mais internos. O processo de degradação iniciou-se pela câmara sub-estomática, avançando através do mesofilo (Figura 2-D). A utilização dos estômatos como porta de acesso não foi encontrada na literatura.

MONSON e BURTON (1972) observaram que a fragmentação experimental da cutícula, com a utiliza- ção de abrasivos, aumentou expressivamente a digestão das forragens. Entretanto, esses autores não relacionaram a importância ou a participação dos estômatos no processo de digestão dos tecidos. Deve ser considerado que as observações do presente trabalho foram realizadas com os materiais intactos. $\mathrm{Na}$ alimentação dos ruminantes, o processo de ruminação garante a dilaceração parcial dos tecidos, expondo maior área para a ação dos microorganismos e descaracterizando parcialmente a barreira imposta pela cutícula.

Foi possível constatar que o potencial de degradação apresentou a seguinte ordem decrescente: tecido parenquimático > floema > epiderme > bainha parenquimática > xilema e esclerênquima, estando de acordo com as seqüências de degradação apresentadas por AKIN et al. (1973), HANNA et al. (1973), AKIN e BURDICK (1975), AKIN e BURDICK (1981), AKIN et al. (1990) e WILSON (1993).

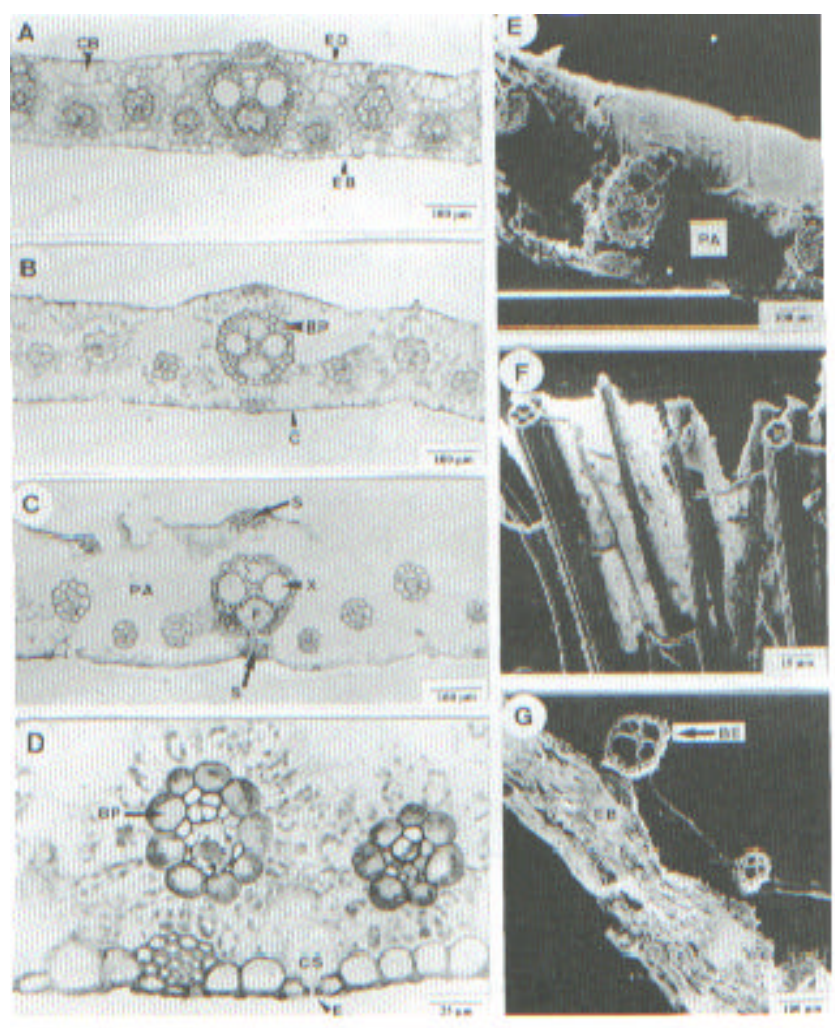

Figura 2 - Secções transversais de $P$. purpureum. Cv. 307-Testo. A - Limbo foliar não incubado; B - Após 6 h de incubação; C - Após 48 h; D - Após 6 h; E - Bainha foliar após 24 h (MEV); F e G - Após 48 h (MEV). Epiderme adaxial (ED); epiderme abaxial (EB); células buliformes (CB); bainha parenquimática (BP); cutícula (C); parênquima (PA); esclerênquima $(\mathrm{S})$; xilema $(\mathrm{X})$; floema $(\mathrm{F})$; estômato $(\mathrm{E})$; câmara sub-estomática (CS); bainha esclerenquimática (BE).

Figure 2 - Cross-sections of P. purpureum Cv. 307-Testo. A - Leaf limbo non-incubated; $B$ - Incubated for $6 h$; $C$ - For 48 ;; $D$ - For $6 h$; $E$ - SEM of leaf sheath for $24 \mathrm{~h}$; F and G - SEM for $48 \mathrm{~h}$. Adaxial epidermis (ED); abaxial epidermis (EB); buliform cells (CB); parenchymabundle sheath $(B P)$; cuticle $(C)$; parenchyma $(P A)$; sclerenchyma (S);xylem $(X)$; phloem $(F)$; stomata $(E)$; substomatal chamber (CS); sclerenchyma bundle sheath (BE). 


\section{Conclusões}

A área ocupada pelo tecido lignificado aumentou com o crescimento das plantas, tanto nas folhas quanto no colmo.

A degradação dos tecidos presentes nas diferentes estruturas diminuiu com a idade da planta, com exceção da bainha foliar, que, devido à presença do aerênquima, tem sua área de degradação aumentada.

A análise anatômica quantitativa da lâmina foliar sugere que o cultivar EMPASC 307 Testo apresenta qualidade inferior como forrageira.

Considerando a área ocupada e também a digestão dos principais tecidos, não houve diferenças entre os cultivares.

\section{Referências Bibliográficas}

AKIN, D.E. 1989. Histological and physical factors affecting digestibility of forages. Agron. J., 81:17-25.

AKIN, D.E. 1993. Perspectives of cell wall biodegradation Session Synopsis. In: JUNG, H.G., BUXTON, D.R. et al. (eds). Forage cell wall structure and digestibility. Madison: ASA/CSSA/SSSA, p.73-82.

AKIN, D.E., AMOS, H.E., BARTON II, F.E. et al. 1973. Microbial degradation of grass tissue revealed by scanning electron microscopy. Agron. J., 65:825-828.

AKIN, D.E., BURDICK, D. 1975. Percentage of tissue types in tropical and temperate grass leaf blades and degradation of tissues by rumen microorganisms. Crop Sci., 15:661-668.

AKIN, D.E., BURDICK, D. 1981. Relationship of different histochemical types of lignified cell walls to forage digestibility. Crop Sci. , 21:577-581.

AKIN, D.E., WILSON, J.R., WINDHAM, W.R. 1983. Site and rate of tissue digestion in leaves of $\mathrm{C} 3, \mathrm{C} 4$ and $\mathrm{C} 3 / \mathrm{C} 4$ intermediate Panicum species. Crop Sci., 23:147-155.

AKIN, D.E., RIGSBY, L.L., LYON, C.E. et al. 1990. Relationship of tissue digestion to textural strength in bermudagrass and alfafa stems. Crop Sci., 30:990-993.

ALVES DE BRITO, C.J.F. Organização estrutural e degradação in vitro de tecidos em Pennisetum purpureum Schum. (Poaceae). Curitiba, 1997. 119p. Dissertação (Mestrado em Botânica) - Setor de Ciências Biológicas, Universidade Federal do Paraná, 1997.

ALVES DE BRITO, C.J.F., ALQUINI, Y. 1996. A new method for staining botanical material embedded in glycol methacrylate. Arq. Biol. Tecnol., 39(4):949-951.

ALVES DE BRITO, C.J.F., ALQUINI, Y., RODELLA, R.A. et al. Alterações histológicas de três ecotipos de capim-elefante (Pennisetum purpureum Schum.), após digestão in vitro. In: REUNIÃO ANUAL DA SOCIEDADE BRASILEIRA DE ZOOTECNIA, 34, 1997, Juiz de Fora - MG.Anais... Juiz de Fora: SBZ, 1997, 2:12-14.

ANDRADE, I.F., GOMIDE, J.A. 1971. Curva de crescimento e valor nutritivo de capim elefante (Pennisetum purpureum Schum.) "A-146 Taiwan". Ceres, 18(100):431-447.

CARO, J.A., SANCHEZ, E. 1969. Las especies de Cynodon (Gramineae) de la Republica Argentina. Kurtziana, 5:191-252.

CORSI, M. Estudo da produtividade e do valor nutritivo do capim elefante (Pennisetum purpureum Schum.), variedade Napier submetido a diferentes frequências e alturas de corte. Piracicaba, 1972. 139p. Tese (Doutorado) - Escola Superior de Agricultura Luiz de Queiroz - ESALQ, 1972.

ESAU, K. 1982. Anatomia de las plantas com semilla. Buenos Aires: Hemisferio Sur. 512 p.

HANNA, W.W., MONSON, W.G., BURTON, G.W. 1973. Histological examination of fresh forage leaves after in vitro digestion. Crop Sci., 13:98-102.

JOHANSEN, D.A. 1940.Plantmicrotechnique. New York: Mc Graw Hill Book. 523 p.

LATHAN, M.J., BROOKER, B.E., PETTIPHER et al. 1978. Ruminococcus flavefaciens cell coat and adhesion to cotton cellulose and to cell walls in leaves of perennial ryegrass (Lolium perenne). Appl. Environ. Microbiol., 43(1):156-165.

McDOUGALL, E.I. 1948. Studies on ruminant saliva. I. The composition and output of sheep's saliva.Biochem. J., 43:99-109.

METCALFE, C.R. 1960. Anatomy of monocotyledons, I. Gramineae. Oxford: Claredon Press. 731p.

MONSON, W.G., BURTON, G.W. 1972. Effects of length of cut and leaf surface treatments on digestibility of fresh forage. Agron. J., 64:405-406.

OTERO, J. R. 1961. Informações sobre algumas plantas forrageiras. 2.ed. Rio de Janeiro: Ministério da Agricultura. $334 \mathrm{p}$.

RODELLA, R.A., AYOUB, J.F., MAIMONI-RODELLA, R.C.S. 1984. Estudos quantitativos de características anatômicas da folha de Panicum maximum Jacq. e Panicum coloratum L. $R$. Agricultura, 59(2):163-174.

RODELLA, R.A., ISHIY, C.M., MAIMONI-RODELLA, R.C.S. et al. 1982. Estudo quantitativo de características anatômicas de folhas de duas espécies de Brachiaria. R. Agrociência, 2(2):21-30.

VENTRELLA, M.C., RODELLA, R.A, COSTA, C. et al. Anatomia e bromatologia de espécies forrageiras de Cynodon Rich. I. Folha. In: REUNIÃO ANUAL DA SOCIEDADE BRASILEIRA DE ZOOTECNIA, 34, 1997, Juiz de Fora MG. Anais... Juiz de Fora: SBZ, 1997a, 2:3-5.

VENTRELLA, M.C., RODELLA, R.A, COSTA, C. et al. Anatomia e bromatologia de espécies forrageiras de Cynodon Rich. II. Caule. In: REUNIÃO ANUAL DA SOCIEDADE BRASILEIRA DE ZOOTECNIA, 34, 1997, Juiz de Fora MG. Anais... Juiz de Fora: SBZ, 1997b, 2:6-8.

WILKINS, R.J. 1969. The potential digestibility of cellulose in forages and feaces. J. Agric. Sci., 73:57-64.

WILKINS, R.J. 1972. The potential digestibility of cellulose in grasses and its relationship with chemical and anatomical parameters. J. Agric. Sci., 78:457-464.

WILSON, J.R. 1976. Variation of leaf characteristics with level of insertion on a grass tiller. II. Anatomy. Aust. J. Agric. Res., 27:355-364.

WILSON, J.R. 1993. Organization of forage plant tissues. In: JUNG, H.G., BUXTON, D.R. et al. Forage cell wall structure and digestibility. Madison: ASA/CSSA/SSSA. p. 1-32. 